Revista Destaques Acadêmicos, Lajeado, v. 10, n. 1, 2018. ISSN 2176-3070

DOI: http://dx.doi.org/10.22410/issn.2176-3070.v10i1a2018.1741

http://www.univates.br/revistas

\title{
MENSURAÇÃO DO CAPITAL INTELECTUAL EM EMPRESA DE CONCRETAGEM E ASFALTAMENTO
}

\author{
Patrícia Secco ${ }^{1}$, Alexandre André Feil ${ }^{2}$
}

Resumo: O capital intelectual é essencial às organizações pelo fato de demonstrar a capacidade e o potencial da geração de riquezas. Neste contexto, este estudo objetiva identificar e analisar o método de mensuração de capital intelectual adequado diante dos dados disponíveis na organização. A metodologia centra-se na abordagem quantitativa, com o uso dos procedimentos técnicos de estudo de caso, pesquisa documental e entrevista não estruturada. A unidade de análise é uma empresa com atividades de concretagem e de asfaltamento de médio porte, localizada estado do Rio Grande do SulBrasil. Os resultados revelam que os modelos market-to-book, a diferença entre o valor de mercado e o valor contábil, e o Q de Tobin centram-se na apuração de valores absolutos e índices, já os modelos Intelect, Stewart e Skandia estratificam os valores absolutos na forma de indicadores e/ou índices. Conclui-se que o modelo Skandia é adequado na mensuração do capital intelectual da Alfa, pois estratifica a mensuração em indicadores, índices e em valor absoluto, o que auxilia na gestão do capital intelectual.

Palavras-chave: Modelos de mensuração. Capital intelectual. Intangível.

\section{INTRODUÇÃO}

O capital intelectual é a soma do conhecimento, informação, propriedade intelectual, softwares e experiências. Está assumindo a posição de principal ativo empresarial em função da geração de riquezas, portanto vem ganhando importância em escala global (ANTUNES; MUCHARREIRA, 2015).

O ativo intangível pode ser considerado uma filosofia de inovação na gestão, por atribuir valor aos produtos e serviços por meio da aplicação da inteligência, sendo assim, é uma ferramenta inovadora na busca de vantagens competitivas (GRACIOLI et al., 2012). Na literatura relacionada a economia, o termo conhecimento classifica-se como equivalente à ativo intangível, já na

1 Bacharel em Ciências contábeis pela Universidade do Vale do Taquari - Univates.

2 Doutor em Qualidade Ambiental pela Universidade Feevale, docente adjunto do Centro de Gestão Organizacional (Ciências Contábeis) e docente permanente do Mestrado em Sistemas Ambientais Sustentáveis (PPGSAS) na Univates. 
literatura gerencial é classificado como capital intelectual (STEFANO et al., 2014).

A gestão empresarial que gerencia apenas os ativos tangíveis não consegue realizar de forma adequada, por exemplo, um cálculo de retorno sobre o ativo, pois em organizações com significativas parcelas de ativos intangíveis, o resultado deste cálculo seria irreal (BONACIM; ARAÚJO, 2010). Estes ainda defendem, que no atual cenário empresarial, o capital intelectual de organizações tem determinado em volume crescente o seu valor econômico. Diante disso, percebe-se a importância da mensuração do capital intelectual, pois se tratando de ativos intangíveis e altamente subjetivos é possível aplicar métodos que os tornem quantificáveis (HOSS; ROJO; GRAPEGGIA, 2009).

Há também dificuldades na mensuração dos ativos intangíveis em função de sua natureza incorpórea (ANTUNES; MUCHARREIRA, 2015) e, segundo Stefano et al. (2014), já foi interpretado como algo que não possui uma realidade. Além disso, uma das restrições na aplicação da mensuração do capital intelectual está na dificuldade de seu gerenciamento, pois geralmente possuem características mais complexas do que os ativos tangíveis (LEV, 2001).

O capital intelectual é um tema que vem ganhando espaço em esfera global, porém sua mensuração não é simples, os modelos e as formas de cálculos são subjetivas e, além disso, não existe um padrão ou um modelo ideal (ANTUNES; MARTINS, 2007). Neste sentido, este estudo objetiva identificar e analisar o método adequado de mensuração do capital intelectual, em função dos dados disponíveis, em empresa de concretagem e asfalto.

A temática deste estudo é essencial, visto que uma organização com mensuração de capital intelectual apresenta uma vantagem competitiva perante seus concorrentes, gera inovações e cria novos produtos, ou seja, pode incorporar rentabilidade e reconhecimento gerencial à empresa (VAZ et al., 2014). Além disso, Antunes (2008) afirma que a Federação Internacional de Contadores (IFAC) está trabalhando para divulgar o conceito do capital intelectual, sua importância e um modelo de mensuração por setor, tendo em vista as particularidades de cada setor econômico.

\section{REFERENCIAL TEÓRICO}

\subsection{Capital intelectual}

No final do século XX foi possível identificar sinais da era da informação, na qual o trabalho físico começou a ser substituído pelo conhecimento (STEWART, 1999). A partir do século XV, verificou-se uma abundância em estudos, especificamente, sobre o capital humano (ANTUNES, 2008). Na década de 1990 se verificou um impulso nos estudos sobre os ativos intangíveis e seu potencial em publicações relacionadas ao capital intelectual (VAZ et al., 2014). 
O conceito de capital intelectual pode ser representado por uma analogia feita por Edvinsson e Malone (1998), entre o capital intelectual e uma árvore. Analisando essa comparação, percebe-se que o caule, os galhos e as folhas são a parte visível da empresa (as demonstrações financeiras, os relatório mensais e anuais); já a parte oculta, as raízes (capital intelectual), é o que torna essa árvore saudável (EDVINSSON; MALONE, 1998). Eles explicam que avaliar uma organização apenas com o que é visível é um erro, pois é necessário avaliar também a parte oculta, ou seja, o capital intelectual que sustenta a organização.

Edvinsson e Malone (1998) destacam que o capital intelectual se divide em três partes: a) Capital humano: relaciona-se ao conhecimento, habilidade e experiência dos funcionários; b) Capital estrutural: é a capacidade organizacional, sistemas, softwares utilizados para armazenar, organizar e apresentar as informações; e c) Capital de clientes: são os relacionamentos de forma contínua com os stakeholders.

A principal dificuldade de mensuração do capital intelectual é o fato de ser um ativo intangível (incorpóreo), porém transformou-se num alvo de interesse (ANTUNES; MUCHARREIA, 2015). Antunes (2008) salienta a limitação em relação a aplicação do capital intelectual relativa à falta de um modelo padrão para a divulgação dessas informações, embora seja de conhecimento que órgãos internacionais, como o International Accouting Standards Committee (IASC), o Financial Accounting Standards Board (FASB) e a Securities Exchange Comission (SEC), tenham patrocinado reuniões para debater o assunto.

\subsection{Modelos de mensuração do capital intelectual}

Nesta subseção apresentam-se os principais modelos utilizados na mensuração do capital intelectual, a saber, Navegador Skandia, Stewart, Diferença entre o valor de mercado e o valor contábil, Razão entre o valor de mercado e o valor contábil (market-to-book), Q de Tobin, Sveiby, Technology Broker - Brooking, Intelect - Euroforum e o Balanced Scorecard.

\subsubsection{Modelo Navegador Skandia}

O navegador Skandia aborda cinco áreas foco (EDVINSSON; MALONE, 1998): 1) Financeira: relaciona-se ao passado da empresa que representa uma medida exata de determinado período temporal e analisado com base no balanço patrimonial; 2) Cliente: é a preocupação em atender bem os clientes e continuar a mantê-los satisfeitos; 3) Humana: centra-se no conhecimento, experiência e habilidade do corpo funcional; 4) Processo: é o uso da tecnologia em benefício próprio, pois os computadores, softwares, intranets, facilitaram as atividades empresariais tornando-as mais rápidas e ágeis; e 5) Renovação e desenvolvimento: é o foco no futuro, a tentativa de projetar um futuro imediato, analisando a empresa no presente e prepará-la adequadamente para o futuro. 
Edvinsson e Malone (1998, p. 166), definiram a Equação 1 para o cálculo do capital intelectual.

$$
\text { Capital Intelectual }=\text { i.C }
$$

A solução desta Equação 1 exigiu a criação de indicadores específicos, para cada um dos cinco focos, que foram agrupados em um total de 21 indicadores para a medida absoluta $(C)$ e mais nove para o coeficiente de eficiência (i) (EDVINSSON; MALONE, 1998). Estes mesmos autores salientam que este modelo de indicadores e índices é flexível, ou seja, dependendo da atividade da empresa em questão esses podem ser alterados.

\subsubsection{Modelo Stewart}

A quantidade ideal de indicadores do modelo stewart são três para cada grupo relacionado ao capital humano, clientes e estrutural (STEWART, 1999). Ainda enfatiza, que para escolher os indicadores corretos deve-se seguir os seguintes princípios: a) Manter a simplicidade: deve ser selecionado até três indicadores para cada grupo, além de um valor que lhe dê uma ideia do todo; b) Avaliar o que é estrategicamente essencial: deve ser analisado a atividade empresarial e escolher indicadores otimizados; e c) Avaliar atividades que produzem riqueza intelectual: deve ser direcionada para itens que ajudam a gerar o capital intelectual, ou seja, riquezas à empresa.

Stewart (1999) apresenta seu navegador de capital intelectual na forma de um gráfico radar. Além disso, destaca que (p. 218-219):

[...] uma empresa real, definiria as escalas de modo que a meta da empresa fosse colocada na extremidade externa, onde o eixo cruza o círculo: para um indicador como razão valor de mercado/valor contábil, poderia incluir $-0,5$ no centro e o valor melhor da classe referente ao setor $(+2,0,+6,0)$ no círculo; para giros de capital, se a empresa registrasse três giros ao ano e nossa meta fosse dobrar esse valor, eu incluiria o valor 3 na metade do eixo e 6 na extremidade.

\subsubsection{Modelo da diferença entre o valor de mercado e o valor contábil}

Este modelo tem a vantagem de ser simples, pois é a diferença entre o valor de mercado e o valor contábil (BASSAN; HAUSCHILDS, 2005). Porém, ainda defendem que no caso de uma empresa ser negociada abaixo do seu valor contábil, significa que esta não possui ativo intelectual, por isso esse modelo é frágil frente às influencias do mercado.

O valor do capital intelectual pode ser calculado por intermédio da Equação 2, conforme Bassan e Hauschildt (2005).

Capital Intelectual $=\mathrm{VM}-\mathrm{VC}$ 
Onde: $\mathrm{VM}=$ valor de mercado (preço por ação multiplicado pelo número total de ações do capital da empresa); e VC = valor contábil (valor registrado no Patrimônio Líquido).

\subsubsection{Modelo da razão entre o valor de mercado e o valor contábil (market- to-book)}

O modelo market-to-book é expresso pela Equação 3 (GOMES, 2003).

Capital Intelectual $=\frac{\mathrm{VM}}{\mathrm{VC}}$

Segundo Stewart (1999, p. 201), se "[...] o valor de uma empresa é maior do que o valor que os acionistas possuem, faz sentido atribuir a diferença ao capital intelectual". Com a utilização do market-to-book é possível comparar empresas do mesmo setor, já que a variação da bolsa de valores afeta as empresas de um mesmo setor de uma forma semelhante (STEWART, 1999). Ele salienta também, que esse modelo de mensuração pode servir como um alerta às organizações, pois caso a razão seja decrescente no decorrer dos anos, significa que alguma atitude deve ser tomada.

\subsubsection{Q de Tobin}

$\mathrm{O} Q$ de Tobin é a razão entre o valor de mercado de um ativo e seu custo de reposição (STEWART, 1999). Além disso, salienta que o objetivo é prever decisões de investimento, por isso o $Q$ de Tobin não é exatamente uma medida de capital intelectual. A Equação 4 apresenta sua forma de apuração (GOMES, 2003).

$$
\mathrm{Q} \text { de Tobin }=\frac{\mathrm{VMA}+\mathrm{VMD}}{\mathrm{VRA}}
$$

Onde: VMA: valor de mercado das ações (ou capital próprio da organização); VMD: valor de mercado das dívidas (ou capital de terceiros empregados); e VRA: valor de reposição dos ativos da organização.

\subsubsection{Modelo de Sveiby}

O Sveiby é um monitor de ativos intangíveis que exibe de uma forma simples uma série de indicadores (SVEIBY, 1998). Ele tem a vantagem de ter uma abordagem simples, porém a escolha dos indicadores é considerada complexa e sem ênfase na área financeira (BASSAN; HAUSCHILDT, 2005).

Os indicadores de Sveiby são adotados de acordo com a estratégia empresarial, classificando-os em três grupos: competência das pessoas, estrutura interna e estrutura externa (BASSAN; HAUSCHILDT, 2005). O objetivo desta avaliação é atingir todos os ativos intangíveis, a fim de que 
cada empresa possa selecionar os seus melhores indicadores (BASSAN; HAUSCHILDT, 2005). Comentam ainda, que em comparação com o navegador Skandia, o foco no cliente equivale a categoria de estrutura externa; foco no processo equivale à categoria de estrutura interna; e o foco humano equivale à categoria da competência.

\subsubsection{Modelo Technology Broker - Brooking}

O technology Broker - Brooking foi inspirado no navegador de Skandia e idealizado por Brooking. Este modelo não define indicadores quantitativos, porém embasa-se na revisão de questões qualitativas, explicando a necessidade de uma metodologia para auditar as informações relacionadas ao capital intelectual (OLIVEIRA et al., 2011).

O Technology Broker é dividido em quatro grupos de ativos intangíveis (BROOKING, 1997): 1) Ativos de mercado: são os ativos que proporcionam competitividade, por exemplo, marcas, razão social da organização e as influências; 2) Ativos humanos: refere-se a importância que as pessoas têm dentro de uma organização, sua capacidade de aprendizado e a transformação desse aprendizado em conhecimento e geração de riquezas à instituição; 3) Ativos de propriedade intelectual: é o valor gerado à empresa por intermédio de um determinado ativo intangível, tendo como característica a proteção por lei, por exemplo, patentes, fórmulas, entre outros; e 4) Ativos de infraestrutura: referem-se aos valores empregados nas tecnologias utilizadas nos métodos e processos empresariais, por exemplo, software, banco de dados, a filosofia e a cultura.

\subsubsection{Modelo Intelect - Euroforum}

O modelo Intelect - Euroforum foi sugerido pelo Grupo Intelect e apresentado no Congresso Euroforum em 1998 (OLIVEIRA et al., 2011). Ainda salientam que este foi o modelo escolhido pela Companhia Paulista de Trens Metropolitanos (CPTM), na região metropolitana de São Paulo, para fazer a mensuração do seu capital intelectual. A Equação 5 representa o cálculo proposto pelo Euroforum.

Valor de mercado $=$ Valor contábil + capital intelectual

Oliveira et al. (2011) salientam que a estrutura do modelo Intelect é dividido em três grupos: a) Blocos: são os ativos intangíveis em função de sua natureza, eles são divididos em capital humano, capital estrutural e capital relacional; b) Elementos: em função da estratégia e de seus fatores críticos, cada empresa deve selecionar os elementos ou ativos intangíveis relevantes; e c) Indicadores: é a forma de medição dos elementos de cada um dos blocos. Esses, para serem eficazes, precisam ter as seguintes características: simples, 
específicos, medíveis, representativos, independentes, positivos e limitados em números.

\subsubsection{Balanced Scorecard}

O Balanced Scorecard entende que a missão e a estratégia de negócio empresarial devem se transformar em medidas tangíveis (KAPLAN; NORTON, 1997). “Em função da necessidade de construir capacidades competitivas de longo alcance, em contraposição ao objeto estático do modelo tradicional da contabilidade financeira" (GOMES, 2003, p. 73).

Kaplan e Norton (1997) desenvolveram o Balanced Scorecard, o qual baseia seus indicadores em quatro perspectivas: a) Financeira; b) cliente; c) Interna; e d) Aprendizado e Crescimento. Nesta perspectiva, encerra-se o referencial teórico e na sequencia descreve-se os procedimentos metodológicos.

\section{PROCEDIMENTOS METODOLÓGICOS}

\subsection{Classificação da pesquisa}

A abordagem do problema desta pesquisa é quantitativa, pois conforme Beuren (2006), esse tipo de pesquisa caracteriza-se pelo emprego da estatística, tanto na coleta quanto no tratamento dos dados. Esta abordagem justificase em função da coleta de indicadores para a aplicação e demonstração de determinados métodos de mensuração de capital intelectual.

O procedimento técnico é um estudo de caso por meio de uma pesquisa documental e entrevista não estruturada. A pesquisa documental baseia-se em materiais que ainda não receberam um tratamento analítico ou que possam ser reelaborados (RICHARDSON, 1985). Gil (2009) enfatiza que a entrevista não estruturada compreendem as pesquisas informais e é comum utilizarse deste tipo de entrevista em estudos de caso. O estudo quanto ao objetivo é uma pesquisa descritiva, pois tem como principal objetivo descrever as características de determinado fenômeno ou população (BEUREN, 2006).

\subsection{Unidade de análise e coleta dos dados}

A unidade de análise centra-se em empresa com a atividade principal de concretagem e asfaltamento, localizada no Estado do Rio Grande do Sul Brasil. A denominação da empresa foi substituída por Alfa em função do sigilo das informações. Sua escolha ocorreu em função da acessibilidade aos dados necessários à pesquisa. Ademais, a Alfa é de médio porte e o regime tributário é o lucro real cumulativo e não cumulativo.

A coleta das informações relacionadas aos indicadores do capital humano, de clientes e estrutural, foram coletados, mediante relatórios gerados pelo próprio software de gestão da Alfa. Caso estes relatórios não alcançassem 
a informação necessária, oportunamente seria aplicada uma entrevista não estruturada.

Os relatórios gerados a partir do software de gestão consistem no faturamento por cliente, faturamento por municípios atendidos, faturamento por produtos vendidos, as informações dos funcionários e investimento com treinamentos e imobilizados, referente ao exercício social de 2016.

As perguntas realizadas na entrevista não estruturada foram: a) qual o grau de qualidade da empresa, pensando em produtos, clientes e estrutura (0 a 100)?; b) qual o grau de eficiência administrativa (contrário de erros administrativos) de 0 a 100?; c) caso o banco de dados precisasse ser substituído hoje, quanto custaria?; e d) qual o índice de motivação dos funcionários/atitude dos funcionários?

Os indicadores e informações coletadas foram organizadas para abastecer os modelos de mensuração do capital intelectual. A realização da entrevista não estruturada com os gestores e o controller da Alfa facilitou a obtenção destes indicadores. A coleta realizou-se entre os meses agosto e setembro de 2017.

\subsection{Tratamento, análise dos dados coletados e limitações do método}

A tabulação dos dados coletados e a aplicação das equações dos métodos de mensuração de capital intelectual realizou-se com o auxílio do Software Microsoft Office Excel. A análise dos valores e comparações entre os métodos teve auxílio de quadros, tabelas e gráficos.

Os métodos de mensuração do capital social selecionados para aplicação neste estudo foram: 1) Razão entre o valor de mercado e o valor contábil market-to-book; 2) Diferença entre o valor de mercado e o valor contábil; 3) Q de Tobin; 4) Modelo Intelect; 5) Navegador Stewart; e 6) Navegador Skandia. Estes modelos foram escolhidos por sugerirem indicadores e equações que a Alfa foi capaz de apresentar e calcular, ou seja, são mais objetivos e por isso facilita a aplicação.

\section{RESULTADOS E ANÁliSES}

\subsection{Perfil sócio econômico}

Os dados coletados para a formação dos indicadores relacionados as questões socioeconômicas são necessários na apuração do capital intelectual (QUADRO 1). 
Quadro 1- Dados sócio econômicos da Alfa referente a 2016

\begin{tabular}{|l|c|c|}
\hline Denominação & Número/valor & Unidade de medida \\
\hline Total de funcionários & 625 & Unidade \\
\hline Rotatividade dos funcionários do administrativo & 3 & Unidade \\
\hline Funcionários fixos & 531 & Unidade \\
\hline Funcionários terceirizados & 21 & Unidade \\
\hline Funcionários temporários & 0 & Unidade \\
\hline Funcionários contratados há 10 anos* & 107 & Unidade \\
\hline Funcionários com mais de 40 anos & 244 & Unidade \\
\hline Funcionários exercendo cargos diretivos & 51 & Unidade \\
\hline Horas investidas em treinamentos & $1.266,8$ & Horas \\
\hline Quantos funcionários foram treinados & 168 & Unidade \\
\hline Quantos clientes estão na empresa há 10 anos* & 23.958 & Unidade \\
\hline Destes 23.958 clientes, quantos compraram em 2016 & 768 & Unidade \\
\hline Quantos clientes novos em 2016 & 2.991 & Unidade \\
\hline Quantos clientes foram atendidos em 2016 & 5.150 & Unidade \\
\hline Total de clientes cadastrados no sistema & 49.173 & Unidade \\
\hline Investimento em R\&D & 0 & Unidade \\
\hline Número de patentes & 0 & Unidade \\
\hline
\end{tabular}

Fonte: Adaptado pelos autores do Software de gestão da Alfa.

Legenda: * Estes indicadores tiveram como base os últimos 10 anos.

O perfil socioeconômico da Alfa revela que possui 531 funcionários, em função do número de filiais e pela atividade operacional que demanda elevado corpo funcional. $\mathrm{O}$ número de clientes é elevado, porém a atividade justifica este número, pelas obras (venda de brita e concreto). As horas de treinamento são consideradas abaixo da média, pois segundo a pesquisa realizada pela associação brasileira de treinamento e desenvolvimento (CARDOSO, 2016), a média no Brasil de treinamento por funcionário em 2016 foi de 3.696 horas.

As informações coletadas em relação ao faturamento por produto e município estão apresentadas na Tabela 1 e 2, respectivamente. As informações da Tabela 1 revelam que o produto com maior destaque no faturamento são as obras rodoviárias, com $62,78 \%$ do faturamento total. 
Tabela 1- Percentual de faturamento por produto, em 2016

\begin{tabular}{c|c}
\hline Produto & \% Sobre o Faturamento total \\
\hline Concreto & $30,86 \%$ \\
\hline Brita & $5,49 \%$ \\
\hline Asfalto & $0,87 \%$ \\
\hline Obras & $\mathbf{6 2 , 7 8 \%}$ \\
\hline
\end{tabular}

Fonte: Adaptado pelos autores do Software de gestão da Alfa.

A Tabela 2 aponta que oito municípios atendidos pela Alfa representam $50 \%$ do faturamento total.

Tabela 2 - Faturamento por município, em 2016

\begin{tabular}{l|c}
\hline Município & \% Sobre o Faturamento \\
\hline Porto Alegre & 11,78 \\
\hline Venâncio Aires & 9,10 \\
\hline Santa Cruz do Sul & 6,65 \\
\hline Estrela & 5,70 \\
\hline Cruz Alta & 4,95 \\
\hline Agudo & 4,79 \\
\hline Lajeado & 3,86 \\
\hline Teutônia & 3,40 \\
\hline
\end{tabular}

Fonte: Adaptado pelos autores do Software de gestão da Alfa.

A Tabela 3 demonstra o faturamento total da Alfa, já descontado das devoluções.

Tabela 3 - Faturamento total, em 2016

\begin{tabular}{l|c}
\hline Receitas & Valores (R\$) \\
\hline Receita de Vendas Cumulativo & $10.997 .571,15$ \\
\hline Receita de Vendas não Cumulativo & $1.075 .973,46$ \\
\hline Receita com Sucatas & $6.978,81$ \\
\hline Outras Receitas Operacionais & $115.558,26$ \\
\hline Receita com Serviço - órgãos públicos & $115.644 .968,33$ \\
\hline Receita com Serviço - particular & $19.685 .678,58$ \\
\hline Receita com Industrialização & $986.426,11$ \\
\hline Serviços de Concretagem & $62.665 .448,58$ \\
\hline (-) Devoluções & $3.906 .370,54$ \\
\hline Total Faturamento & $\mathbf{2 0 7 . 2 7 2 . 2 3 2 , 7 4}$ \\
\hline
\end{tabular}

Fonte: Adaptados pelos autores das demonstrações contábeis da Alfa. 
A rentabilidade é o resultado do lucro líquido dividido pelo total do investimento, ou seja, o ativo total (EQUAÇÃO 7).

$$
\text { Rentabilidade }=\frac{\text { Lucro Líquido }}{\text { Ativo total }}=\frac{-352.422,94}{450.478 .729,10}=-0,00078
$$

A coleta de alguns dados exigiu pesquisas externas à Alfa, por exemplo, o valor que o Rio Grande do Sul investiu em obras rodoviárias em 2016 e a rentabilidade da concorrência. Neste sentido, segundo Cunha Neto (2016) o Departamento Autônomo de Estradas de Rodagem (DAER) investiu 333 milhões de reais em obras rodoviárias. A rentabilidade da concorrência foi apurada por meio de corporações do mesmo ramo de atuação com ações na BM\&FBovespa (TABELA 4).

Tabela 4 - Rentabilidade da concorrência, em 2016

\begin{tabular}{l|c|c|c}
\hline Empresas Bovespa & $\begin{array}{c}\text { Lucro } \\
\text { exercício }\end{array}$ & $\begin{array}{c}\text { Investimento } \\
\text { total }\end{array}$ & Rentabilidade \\
\hline Conc Rodovias do tietê S/A & $-21.263,00$ & $1.593 .231,00$ & $-0,01$ \\
\hline Ecorodovias Concessões e Serviços S/A & $238.108,00$ & $6.104 .720,00$ & 0,04 \\
\hline Ecorodovias Infraestrutura e Log S/A & $-1.111 .799,00$ & $6.603 .407,00$ & $-0,17$ \\
\hline Empresa Conc Rodov do norte S/A & $-4.653,00$ & $387.770,00$ & $-0,01$ \\
\hline Rodovias das Colinas S/A & $86.739,00$ & $1.877 .094,00$ & 0,05 \\
\hline Total média rentabilidade & & & $-0,02$ \\
\hline
\end{tabular}

Fonte: Elaborado pelos autores.

O valor de mercado foi apurado com base na Equação 5, conforme Milone (2004). O valor dos ativos tangíveis e intangíveis foram encontrados no balanço patrimonial na parte do ativo.

Valor de mercado $=$ Ativos tangíveis + Ativos intangíveis

Valor de mercado $=448.224 .205,00+2.254 .524,07$

Valor de mercado $=450.478 .729,00$

Os indicadores subjetivos foram apurados com base nas entrevistas com os gestores da Alfa e no Quadro 2 apresenta-se as questões realizadas, suas respostas e os respondentes. 
Quadro 2 - Indicadores subjetivos

\begin{tabular}{|l|l|c|l|}
\hline Indicador & Pergunta & $\begin{array}{l}\text { Resposta/Nota } \\
\text { de 0 a 100 }\end{array}$ & $\begin{array}{l}\text { Quem } \\
\text { respondeu }\end{array}$ \\
\hline $\begin{array}{l}\text { Índice de motivação dos } \\
\text { funcionários/Atitude } \\
\text { dos funcionários }\end{array}$ & $\begin{array}{l}\text { Qual é o índice de motivação } \\
\text { dos funcionários / Atitude dos } \\
\text { funcionários? }\end{array}$ & $\begin{array}{l}\text { Média de 70,17 } \\
\text { qualidade }\end{array}$ & $\begin{array}{l}\text { Gerente de } \\
\text { Recursos } \\
\text { Humanos }\end{array}$ \\
\hline $\begin{array}{l}\text { Desempenho/meta de } 0 \text { 100, qual o grau de } \\
\text { qualidade da empresa, pensando } \\
\text { em produtos, clientes e estrutura? }\end{array}$ & $\begin{array}{l}\text { Produto: 80,5 } \\
\text { Cliente: 70,0 } \\
\text { Estrutura: 80,0 } \\
\text { Média: 76,83 }\end{array}$ & Controller \\
\hline $\begin{array}{l}\text { Eficiência } \\
\text { administrativa/receitas }\end{array}$ & $\begin{array}{l}\text { De 0 a 100, qual o grau de } \\
\text { eficiência administrativa (contrário } \\
\text { de erros administrativos)? }\end{array}$ & Controller \\
\hline $\begin{array}{l}\text { Custo de substituição } \\
\text { do banco de dados }\end{array}$ & $\begin{array}{l}\text { Caso precisasse substituir o banco } \\
\text { de dados hoje, quanto custaria? } \\
\text { (R\$) }\end{array}$ & $400.000,00$ & $\begin{array}{l}\text { Gerente de } \\
\text { TI }\end{array}$ \\
\hline
\end{tabular}

Fonte: Elaborado pelos autores.

O indicador relacionado a satisfação de clientes foi coletado junto a análise do clima organizacional da Alfa. Nesta pesquisa consta a satisfação de cada cliente, separadamente, após realizar a média de todos os resultados o total ficou em $85,72 \%$ de satisfação. E, por último, foram coletadas as medidas absolutas para o navegador Skandia (QUADRO 13).

\section{Quadro 3 - Medidas absolutas Navegador Skandia}

\begin{tabular}{|l|c|}
\hline Indicadores da Mensuração Absoluta do Capital Intelectual (C) & Valores (R\$) \\
\hline $\begin{array}{l}\text { Receitas resultante da atuação em novos negócios (novos programas/ } \\
\text { serviços) }\end{array}$ & - \\
\hline Investimento no desenvolvimento de novos mercados & $32.152,90$ \\
\hline Investimento no desenvolvimento do setor industrial & $942.605,64$ \\
\hline Investimento no desenvolvimento de novos canais & - \\
\hline Investimento em TI aplicada a vendas, serviço e suporte & $194.070,91$ \\
\hline Investimento em TI aplicada à administração/Novos equipamentos de TI & $164.403,73$ \\
\hline Investimento no suporte aos clientes & - \\
\hline Investimento no serviço aos clientes & $149.098,24$ \\
\hline Investimento no treinamento de clientes & - \\
\hline Despesas com os clientes não-relacionadas ao produto & - \\
\hline Investimento no desenvolvimento da competência dos empregados & $27.559,25$ \\
\hline $\begin{array}{l}\text { Investimento em sup. treinamento relativo a novos produtos para os } \\
\text { empregados }\end{array}$ & - \\
\hline $\begin{array}{l}\text { Treinamento direcionado aos emp. que não trabalham nas instalações da } \\
\text { empresa }\end{array}$ & - \\
\hline
\end{tabular}




\begin{tabular}{|l|c|}
\hline Indicadores da Mensuração Absoluta do Capital Intelectual (C) & Valores (R\$) \\
\hline Investimento em trein., com. e sup. emp. permanentes em períodos integral & $9.733,39$ \\
\hline $\begin{array}{l}\text { Programas de treinamento e suporte aos emp. temporários em período } \\
\text { integral }\end{array}$ & - \\
\hline $\begin{array}{l}\text { Programas de treinamento e suporte aos empregados temporários de tempo } \\
\text { parcial }\end{array}$ & - \\
\hline Investimento no desenvolvimento de parcerias/joint-ventures & - \\
\hline Upgrades ao EDI ou à rede eletrônica de dados & $19.834,00$ \\
\hline Investimento na identificação da marca (logotipo/nome) & $3.260,00$ \\
\hline Investimento em novas patentes e direitos autorais & - \\
\hline
\end{tabular}

Fonte: Elaborado pelos autores.

Após a coleta destas informações, na sequencia apura-se o valor do capital intelectual.

\subsection{A mensuração do capital intelectual}

\subsubsection{Modelos de mensuração de capital intelectual sem o uso de indicadores}

Nesta subseção apresenta-se os modelos relacionados a razão entre o valor de mercado e o valor contábil (market-to-book), a diferença entre o valor de mercado e valor contábil e o Q de Tobin. Estes são os métodos considerados simples para apuração, pois não possuem indicadores, ou seja, os valores aplicados na equação são absolutos. Neste caso, por exemplo, o valor contábil é o valor do Patrimônio Líquido que está no balanço patrimonial, não é preciso fazer nenhum cálculo para obter este valor, essa lógica serve para os demais valores.

O modelo razão entre o valor de mercado e o valor contábil (market-tobook) foi apurado com base na Equação 3.

$$
\text { Capital Intelectual }=\frac{\text { Valor de Mercado }(\mathrm{VM})}{\text { Valor Contábil }(\mathrm{VC})}=\frac{450.478 .729,00}{255.487 .748,28}=1,76
$$

O resultado revela que a Alfa possui um valor empresarial que não está sendo considerado na contabilidade. Segundo Santanna, Teixeira e Louzada (2003) se o resultado for maior que 1, significa que o mercado está reconhecendo um valor que não está registrado pela contabilidade. Este método permite também a comparação dos resultados com a concorrência e sua apuração anual poderia auxiliar na comparação com a própria evolução ao longo do tempo.

Em 2016, por exemplo, a razão encontrada foi de 1,76, nos próximos anos o ideal é que esta razão aumente, ou seja, o valor de mercado deve aumentar proporcionalmente à inflação para não ficar abaixo da concorrência. $O$ ponto negativo deste método é relativo ao valor das ações da bolsa de valores ou a 
economia, pois se desestabilizam por motivos aleatórios, logo a mensuração do capital intelectual também é afetada. Na sequência apresenta-se o próximo modelo de mensuração.

O modelo da diferença entre o valor de mercado e o valor contábil foi apurada com base na Equação 2.

$$
\begin{gathered}
\text { Capital Intelectual = VM - VC } \\
\text { Capital Intelectual }=450.478 .729,00-255.487 .748,28 \\
\text { Capital Intelectual }=194.990 .981,00
\end{gathered}
$$

Nesta equação utiliza-se os mesmos valores do market-to-book, a única diferença é que neste caso apura-se valores absolutos. Neste sentido, a diferença entre o valor de mercado e valor contábil não é comumente indicada para utilização, pois além da oscilação de valor, o fato de não ser um indicador dificulta a comparação com a concorrência e também da própria empresa, para sua análise anual. Além deste modelo apresenta-se a aplicação do modelo Q de Tobin.

O modelo Q de Tobin necessita do valor do capital próprio (patrimônio líquido), o valor de mercado das dívidas (passivo circulante e passivo não circulante) e o valor de reposição dos ativos (imobilizado) (ver EQUAÇÃO 4).

$$
\mathrm{Q} \text { de Tobin }=\frac{\mathrm{VMA}+\mathrm{VMD}}{\mathrm{VRA}}=\frac{255.487 .748,28+194.990 .981,00}{179.778 .781,53}=2,50
$$

$\mathrm{O} Q$ de Tobin revela um valor razão da capacidade de investimento da Alfa. O resultado 2,50 é um valor favorável, pois significa que o ativo ou capacidade de investimento da Alfa é duas vezes e meia maior do que o valor de reposição do ativo.

\subsubsection{Modelos de mensuração de capital intelectual com o uso de indicadores}

Os modelos de mensuração de capital intelectual utilizados com base em indicadores correspondem ao Stewart, Skandia e o Intelect - Euroforum. O Intelect - Euroforum, apesar de sugerir uma equação de cálculo, é apurado com vínculos subjetivos. Neste sentido, apresenta-se um esquema do capital intelectual, no qual estão relacionados os indicadores do modelo (FIGURA 1). 
Figura 1 - O capital intelectual - modelo Intelect

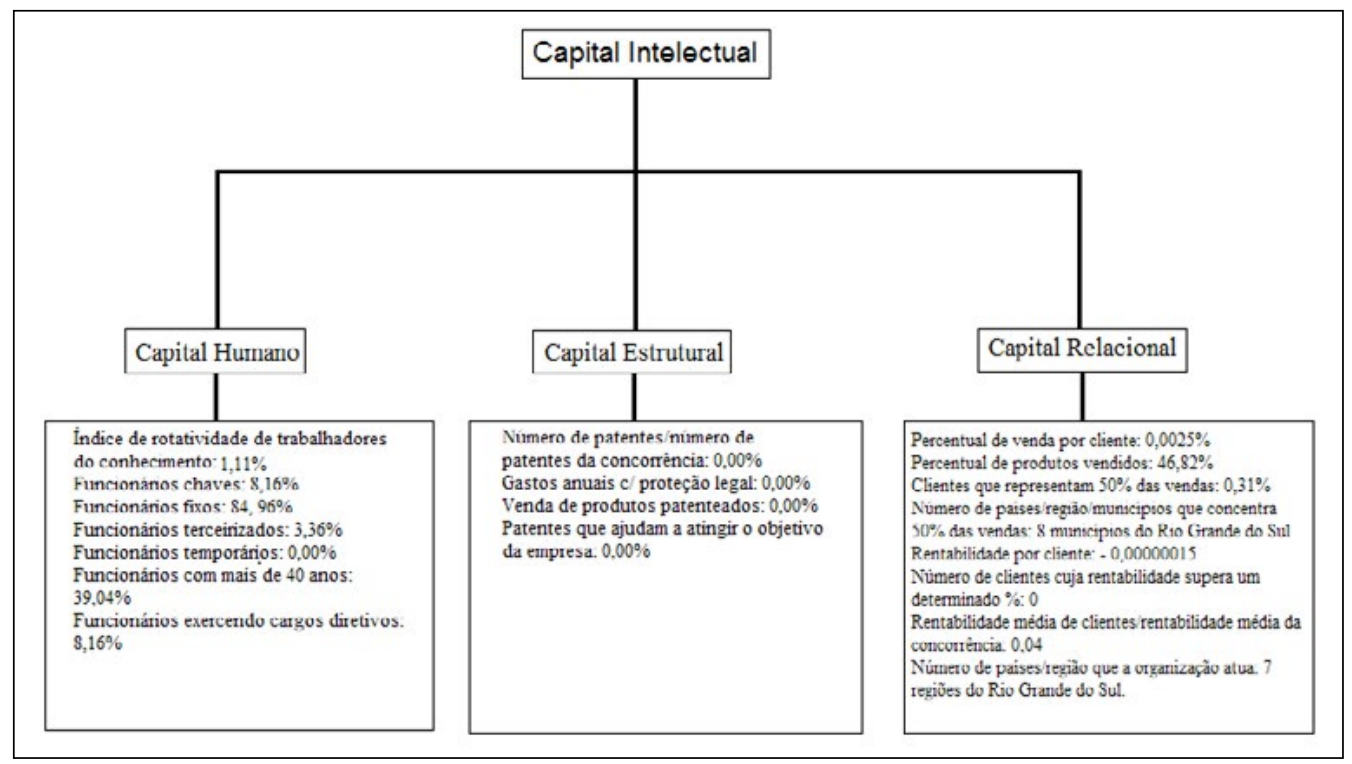

Fonte: Elaborado pelos autores.

Os índices do capital humano foram encontrados por intermédio de cálculos de representatividade, ou seja, cálculo de porcentagem. O capital estrutural teve como foco principal as patentes, mas como pode ser observado a Alfa não possui produto patenteado, sendo assim, os índices deste bloco ficaram zerados. Os índices do capital relacional foram encontrados por intermédio do mesmo cálculo do capital humano, com exceção do percentual de produtos vendidos e outros que não necessitaram de cálculo.

O modelo intelect possui vários indicadores, segregados nos três blocos do capital intelectual, o que oferece uma visão ampla da Alfa, possibilitando uma análise completa do capital intelectual. Este modelo de mensuração é voltado a área gerencial, pois apresenta apenas os índices, sem a apuração do valor absoluto. Diante disso, percebe-se que o modelo intelect é útil para avaliar cada indicador, separadamente, apontar se algum necessita de melhorias.

$\mathrm{O}$ intelect aponta que a Alfa apresenta os índices zerados no bloco estrutural, contudo isso ocorreu em função da sua atividade empresarial. Não é comum patentear traços de concreto nem obras rodoviárias, por isso estes índices poderiam ser adaptados à sua atividade e porte. Ademais, na sequencia apresenta-se o modelo Stewart.

O modelo Stewart não sugere forma de cálculo e é apresentado em formato de gráfico aranha (GRÁFICO 1), mostrando os valores dos indicadores reais da empresa em relação a meta desejada. 
Gráfico 1 - Apresentação do modelo Stewart

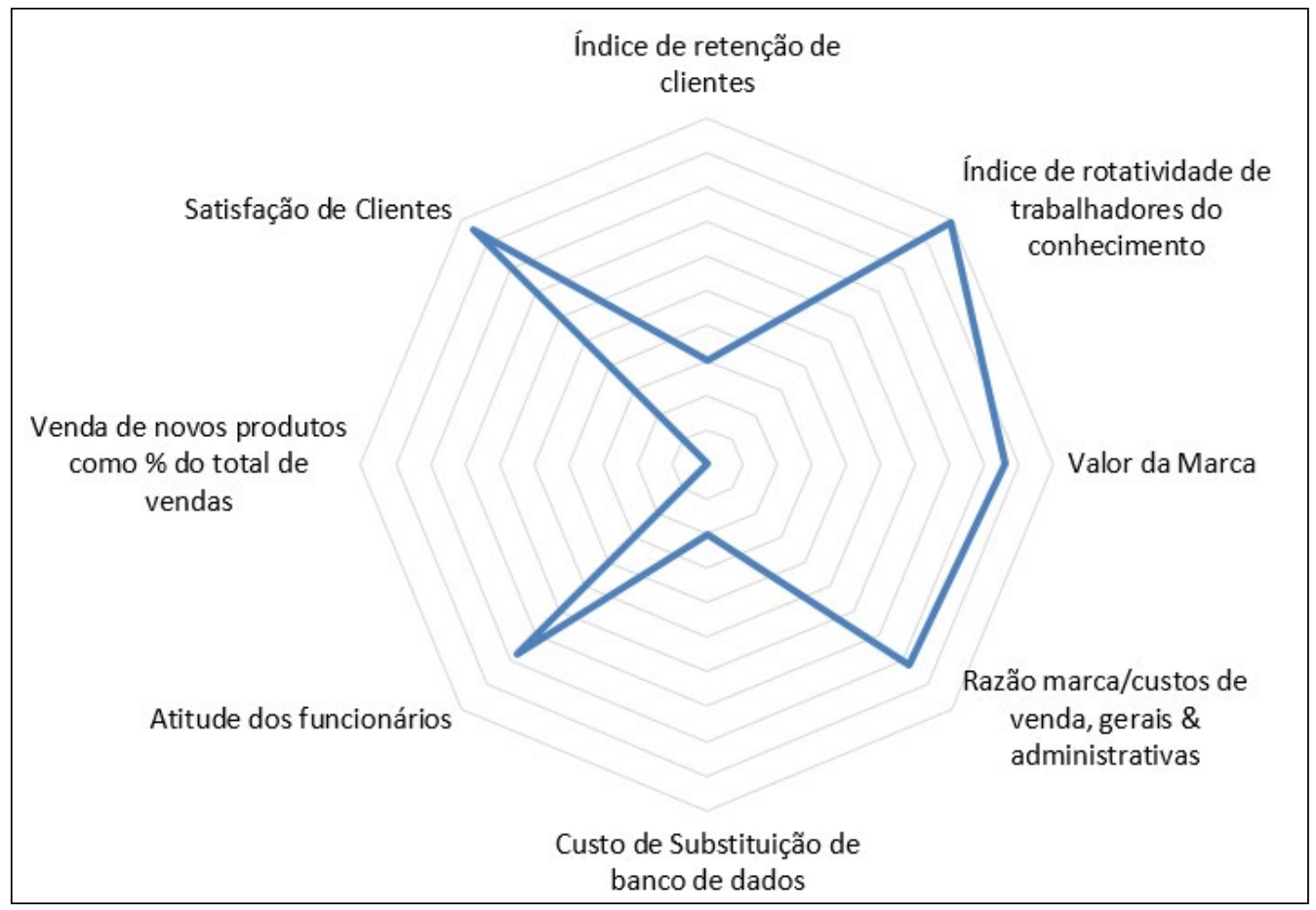

Fonte: Elaborado pelos autores.

O Gráfico 1 revela os índices que estão mais próximos das metas da Alfa. A maioria deles estão próximos com exceção do índice de retenção de clientes, custo de substituição de banco de dados e venda de novos produtos com percentual total de vendas (GRÁFICO 1; QUADRO 4). Diante disso, percebe-se que estes três índices são os que merecem maior atenção dos gestores.

\section{Quadro 4 - Indicadores Modelo Stewart}

\begin{tabular}{|l|c|c|c|c|}
\hline Indicador & Real & Meta & Base $\%$ & Observação \\
\hline Índice de retenção de clientes & 0,03 & 0,10 & 30,00 & Quanto $>$ melhor \\
\hline Índice de rotatividade & 0,01 & 0,00 & 99,00 & Quanto $<$ melhor \\
\hline Valor da Marca (em reais) & 422.049 .967 & 490.000 .000 & 86,13 & Quanto > melhor \\
\hline Razão marca/custos de venda & 2,46 & 3,00 & 82,00 & Quanto > melhor \\
\hline Custo de Subst.Banco dados & $400.000,00$ & $500.000,00$ & 20,00 & Quanto $<$ melhor \\
\hline Atitude dos funcionários & 0,70 & 0,90 & 77,78 & Quanto > melhor \\
\hline Venda de novos produtos & 0,00 & 0,01 & 0,00 & Quanto > melhor \\
\hline Satisfação de Clientes & 0,86 & 0,90 & 95,56 & Quanto > melhor \\
\hline
\end{tabular}

Fonte: Elaborado pelos autores. 
Vale ressaltar que o índice de venda de novos produtos está zerado, pois em 2016 a Alfa entrou no mercado com o produto argamassa, então naquele ano ocorreram os investimentos e, provavelmente, em 2017 a empresa sentirá os reflexos deste investimento. O modelo Stewart volta-se à gestão empresarial, pois não apresenta um valor único e monetário, mas indicadores para auxiliar a gestão do capital intelectual. Após apresentar o modelo Stewart, na sequencia descreve-se o modelo Skandia.

O Navegador Skandia foi aplicado a partir das medidas absolutas (QUADRO 3) e dos índices de coeficiente de eficiência (QUADRO 5).

Quadro 5 - Índices do coeficiente de eficiência Navegador Skandia

\begin{tabular}{|l|c|}
\hline Índice do Coeficiente de Eficiência (i) do Capital Intelectual & Valores \% \\
\hline Participação de mercado & 39,08 \\
\hline Índice de satisfação dos clientes & 85,72 \\
\hline Índice de liderança & 8,16 \\
\hline Índice de motivação & 70,17 \\
\hline Índice de investimento em R\&D/investimento total & 0,00 \\
\hline Índice de horas de treinamento & 34,27 \\
\hline Desempenho/meta de qualidade & 76,83 \\
\hline Retenção dos empregados & 17,12 \\
\hline Eficiência administrativa/receitas & 60,00 \\
\hline
\end{tabular}

Fonte: Elaborado pelos autores.

O Skandia apura o capital intelectual por meio da Equação 1, sendo a soma das medidas absolutas multiplicado pela média dos índices do coeficiente de eficiência.

$$
\begin{gathered}
\text { Capital Intelectual }=\text { i.C } \\
\text { Capital Intelectual }=1.542 .718,06 \text { x 43,48\% } \\
\text { Capital Intelectual }=670.773,81
\end{gathered}
$$

Este modelo de mensuração pode ser considerado o mais completo deste estudo, pois além de apresentar vários indicadores, também calcula o valor absoluto. Diante do resultado deste método, pode-se perceber que os objetivos da Alfa, por meio deste estudo, foram alcançados, pois a mensuração do capital intelectual foi realizada mediante diversos indicadores abrangendo os três blocos, gerando assim uma visão holística da empresa. 


\section{CONCLUSÃO}

Este estudo serviu para identificação e análise do método de mensuração de capital intelectual adequado à Alfa. Essa mensuração oferece à Alfa um diferencial perante a concorrência, uma vez que o capital intelectual demonstra a capacidade da empresa em gerar riquezas.

Os resultados revelam que os dados socioeconômicos necessários na formação dos índices e indicadores foram indispensáveis na mensuração do capital intelectual. A aplicação destas informações nos modelos de mensuração apresentaram informações distintas, ou seja, cada método tem uma forma de apresentação dos indicadores/índices.

Os modelos de mensuração apontam que o Intelect, Stewart e o Skandia são voltados à gestão empresarial, pois apresentam os indicadores de uma forma ampla, isto é, eles são apresentados separadamente e, a partir disso, a empresa pode identificar pontos fracos e pontos fortes. Por outro lado, o marketto-book, diferença entre o valor de mercado e o valor contábil, e o Q de Tobin apresentam valores absolutos, neste caso, o cálculo não se identifica com as características da Alfa. Por fim, o Navegador Skandia foi aplicado e percebeu-se que este é o método de mensuração indicado à Alfa, pois além de apresentar indicadores importantes, também calcula um único valor absoluto de capital intelectual.

\section{REFERÊNCIAS}

ANTUNES, Maria Thereza Pompa. Capital Intelectual. 1. ed. São Paulo: Atlas, 2008.

ANTUNES, Maria Thereza Pompa; MARTINS, Eliseu. Capital intelectual: seu entendimento e seus impactos no desempenho de grandes empresas brasileiras. Revista de administração e Contabilidade da Unisinos, v. 4, n. 1, p. 5-21, 2007.

ANTUNES, Marina; MUCHARREIRA, Pedro Ribeiro. Os Intangíveis no Balanced Scorecard: A sua Relevância na Gestão Empresarial e na Estratégia do Negócio.

Portuguese Journal of Finance, v. 1, n. 1, p. 104-120, 2015.

BASSAN, Cristiane Cerve; HAUSCHILDT, Rogério. Mensuração do Capital Intelectual: Um desafio importante para a Contabilidade. Revista Eletrônica de Contabilidade, v. 1, n. 2, p. 106, 2004.

BEUREN, Ilse Maria. Como Elaborar Trabalhos Monográficos em Contabilidade. 3. ed. SãoPaulo: Atlas, 2006.

BONACIM, Carlos Alberto Grespan; ARAUJO, Adriana Maria Procópio de. Influência do capital intelectual na avaliação de desempenho aplicada ao setor hospitalar. Ciênc. saúde coletiva, v. 15, n. 1, p. 1249-1261, 2010. 
BROOKING, A. El capital intelectual - el principal activo de las empresas del tercer milenio. Barcelona: Ed. Paidós Ibérica, S.A. 1997.

CARDOSO, Fernando. O Panorama do Treinamento no Brasil: Fatos, Indicadores, Tendências e Análises. 2016. Disponível em: <http:/ / www.integracao.com.br/ pesquisa-panorama-do-treinamento-no-brasil-2016.pdf>. Acesso em: 14 de jan. 2018.

CUNHA NETO, Júlio. Investimentos do Daer em rodovias atingem R $\$ 333$ milhões em 2016. 2016. Disponível em: < http:/ / www.daer.rs.gov.br/ investimentos -do-daer-emrodovias-atingem-r-333-milhoes-em-2016>. Acesso em: 14 de jan. 2018.

EDVINSSON, Leif; MALONE, Michael S. Capital Intelectual: descobrindo o valor real de sua empresa pela identificação de seus valores internos. São Paulo: Makron Books, 1998.

GIL, Antonio Carlos. Estudo de Caso. 1. ed. São Paulo: Atlas, 2009.

GOMES, Marcelo Jota. Análise do modelo de avaliação de intangíveis proposto por Sveiby (1998) em empresas de base tecnológica no estado de Pernambuco. 2003. 185p. 2003. Tese de Doutorado. Dissertação (Mestrado em Ciências Contábeis). UNB/ UFPB/UFPE/UFRN, 2003.

GRACIOLI, Clarissa et al. Capital Intelectual: Uma Ferramenta Inovadora na Busca por Vantagens Competitivas. RAI Revista de Administração e Inovação, v. 9, n. 4, p. 96-120, 2012.

HOSS, O.; ROJO, C. A.; GRAPEGGIA, M. Gestão de Ativos Intangíveis. São Paulo: Atlas, 2009.

KAPLAN, Robert S.; NORTON, David P. A Estratégia em Ação: Balanced Scorecard. 19. ed. Rio de Janeiro: Elsevier, 1997.

LEV, B. Intangibles: Management, Measurement and Reporting. Brookings Institution, Washington, 2001.

MILONE, Mario César de Mattos. Cálculo do Valor De Ativos Intangíveis: Uma Metodologia Alternativa para a Mensuração do Valor de Marcas. 124 f. 2004. Tese Doutorado, Universidade de São Paulo, 2004.

OLIVEIRA, Elizabeth Castro Maurenza; ARNOSTI, José Carlos Melchior; YOMURA, Nobuya; NEUMANN, Regina Aparecida. Capital Intelectual: Reconhecimento e Mensuração. 1. ed. Curitiba: Juruá, 2011.

RICHARDSON, Roberto Jarry. Pesquisa Social. São Paulo: Atlas, 1985.

SANTANNA, Dimitri Pinheiro de; TEIXEIRA, Aridelmo José Campanharo; LOUZADA, Luiz Cláudio. A relação entre market-to-book equity e lucros anormais no mercado de capitais no Brasil. In: XXVII ENANPAD, 2003, Atibaia(SP). 
STEFANO, Nara Medianeira et al. Gestão de Ativos Intangíveis: Implicações e Relações da Gestão do Conhecimento e Capital Intelectual. Perspectivas em Gestão e Conhecimento, João Pessoa, v. 4, n. 1, p. 22-37, 2014.

STEWART, Thomas A. Capital Intelectual: A nova vantagem competitiva das empresas. 4. ed. Rio de Janeiro: Campus, 1998.

SVEIBY, Karl Erik. A Nova Riqueza das Organizações: gerenciando e avaliando patrimônios de conhecimento. Rio de Janeiro: Campus, 1998.

VAZ, Caroline Rodrigues; et al. Modelos de Mensuração do Capital Intelectual para Tomada de Decisão e Variáveis de Desempenho. Iberoamerican Journal of Industrial Engineering, Florianópolis, SC, v. 6, n. 11, p. 245-260, 2014. 